\title{
Pricing Models of e-Books When Competing with p-Books
}

\author{
Yan $\mathrm{Li}^{1,2}$ and Nan $\mathrm{Liu}^{1}$ \\ ${ }^{1}$ School of Management, Zhejiang University, Hangzhou 310058, China \\ ${ }^{2}$ School of Business, Shandong University at Weihai, Weihai 264209, China \\ Correspondence should be addressed to Nan Liu; nliu@zju.edu.cn
}

Received 17 April 2013; Revised 28 June 2013; Accepted 28 June 2013

Academic Editor: Matjaz Perc

Copyright (C) 2013 Y. Li and N. Liu. This is an open access article distributed under the Creative Commons Attribution License, which permits unrestricted use, distribution, and reproduction in any medium, provided the original work is properly cited.

With the rise in popularity of e-books, there is a growing need to reexamine the pricing strategy in the e-book supply chain. In this paper, we study two forms of pricing models widely used in the book industry: wholesale and agency pricing models. We first assume a stylized deterministic demand model in which the demand depends on the price, the degree of substitution, and the overall market potential. Subsequently, we employ the game theory to determine the price equilibriums and profit distribution under different pricing models. Finally, we explore the behavior of the publisher and the retailer under different preferences and degrees of substitution through a computational study. Our findings indicate that the e-book price will be lower under the agency pricing model than under the wholesale pricing model, which is counterintuitive. The publishers have higher incentives to adopt the agency pricing model than the wholesale pricing model. The agency pricing model benefits the whole system and can provide readers with books at lower prices. The degree of substitution between the two forms of books and the readers' preference toward e-book will affect the books' price and the profit distribution between the publisher and the retailers.

\section{Introduction}

As e-books have become more popular, there is a growing need to examine the pricing strategy and coordination issues in the book supply chain. To promote e-book sales and readership, Amazon sets e-book prices at a low level, which consequently brought publishers the fear that e-book sales would cannibalize the sales of conventional paper books and hurt their profits. Therefore, to force Amazon to abandon its low-price strategy, HarperCollins and five other publishers settled a new contract with e-book retailer Apple to price the e-books under the agency pricing model. This move resulted in the emerging discussion of the difference between conventional wholesale pricing and the agency pricing model. To the best of our knowledge, only a few studies have dealt with the differences between these two kinds of pricing models when considering the competition between e-books and conventional paper books. The present study is an attempt to analyze the different prices of the books and the different behaviors of publishers and retailers under these two different pricing models.
This paper aims to explore how the agency pricing model affects the prices of books, the participants' strategic behaviors, and the profit distribution between two competing book retailers. Specifically, we ask the following questions.

(i) Should we always expect e-book prices to be higher under the agency pricing model than under the conventional wholesale pricing model?

(ii) Do publishers receive more profit under the agency pricing model? Does the agency pricing model benefit the whole system?

(iii) Does the degree of substitutability between the two forms of books affect the equilibriums? How do other factors such as reader's preference and the autonomy of the e-book retailers affect the results?

Our motivation for this research comes from several different sources, namely, digital supply chain coordination, dual-channel supply chain, and pricing modes of the information goods and the shift from p-books to e-books. 
(1) Most of the previous studies on digital supply chains have explored the impact of piracy on the digital goods industries, especially in the software and music industries. For example, Chellappa and Shivendu [1] demonstrate that the contractual strategies in the physical product supply chains are often inapplicable to digital product manufacturers and retailers because of piracy. Feng [2] obtained similar results to those of Chellappa and Shivendu [1]. Jeong et al. [3] explore the impact of piracy on the digital music supply chain and analyze two contract types: fixed fee contract and per song contract. Their findings show that a fixed fee full transfer contract always coordinates with the supply chain. Khouja and Wang [4] find that piracy affects the decisions on channel selection and profit distribution. Khouja and Park [5] and Khouja and Smith [6] analyze the pricing policy of information goods under piracy. All these studies were conducted by disregarding the competition and cannibalization effect of digital goods on physical goods. Danaher et al. [7] analyze the impact of digital distribution on physical sales and piracy through a quasiexperimental study. Their results show that the correlation between digital distribution and piracy is strong, although the substitution between digital distribution and physical sales is not significant for the DVD industry. Deleersnyder et al. [8] also show that the fear of cannibalization in the newspaper industry has been largely overestimated.

(2) Many researchers have focused on dual-channel competitions and coordination in supply chain managements. Most of the literature studied the impact of internet channels on conventional retail channels. Several available review papers excellently addressed the impact of the internet on supply chain management, such as Keshinocak and Tayur [9], Cattani and Gilland [10], and Agatz et al. [11].

Although the introduction of a second channel may attract more customers and improve sales, it may also undermine the existing channel relationships through possible competition and cannibalization. Nevertheless, some studies show that the competition and cannibalization effects are not as fierce as we expected. Lal and Sarvary [12] find that rather than intensifying price competition, introducing an internet channel can actually reduce it. Biyalogorsky and Naik [13] develop a method to facilitate the assessment of the impact of online activities on offline sales and find that online sales do not cannibalize retail sales significantly. Cai [14] analyzes whether the supplier and the retailer benefit from the addition of a new channel to the traditional single-channel supply chain, and their results indicate that it depends on such factors as channel base demand, channel operational costs, and channel substitutability. Likewise, Jeffers and Nault's [15] findings show that consumers do not benefit from a multichannel strategy when the disutility of buying online and shipping costs are relatively low. Forman et al. [16] empirically prove that the disutility of buying online will affect the channel cannibalization. Huang and Swaminathan [17] study the optimal pricing strategy after the introduction of an internet retail channel. In a recent study, Lu and Liu [18] analyze the pricing games in a distribution system, in which a supplier sells a common product through a conventional channel (physical retailer) and an e-commerce channel (e-tailers), with a focus on the dual-channel system model. All these studies indicate that although internet channels have many advantages over traditional retail channels, they will remain to coexist for a long time.

(3) There are some studies which have been conducted on the pricing models of information goods and the shift from p-books to e-books. For example, Jain and Kannan [19] have made the comparison between connected-time pricing strategy and search-based and subscription-fee pricing strategy. Chen and Seshadri [20] analyze the pricing strategy of the information goods when the customers are heterogeneous with regard to both marginal willingness to pay for the quality and outside opportunity. Most previous of the studies focus on how the information product is priced rather than who should price the information goods and most of these studies do not consider the cooperation between the supply chain participants. As for the cooperation between the powerful retailer like Amazon.com and some small publishers, the barging result is the ultimatum game, and we refer the readers to the works by Szolnoki et al. [21, 22].

The studies conducted on the shift from p-books to ebooks show that although the e-books have a lot of advantage over p-books, p-books and e-books will coexist for a long time because of some reasons like readers' reading habit, low acceptance, and so on. The advantages of e-books were described as "instant, desktop access, ability to keyword search, portability," (see Shelburne [23]) being convenient for statistical analysis (e.g., for computational linguistic analysis like [24-26]). The e-books also are facing some challenges. Pölönen et al. [27] demonstrate that reading from a hard copy was more comfortable than reading from e-books. Woody et al. [28] also find that students do not prefer ebooks for depth study. Huang and Hsieh [29] find that the consumer's perceived attributes will directly affect their acceptance behaviors and also influence their behavior via perception of the costs. In a word, although e-books have a lot of advantages over p-books, there are still some readers who prefer $\mathrm{p}$-books to e-books now.

Only a few studies have been conducted on the impact of e-books on the sales of physical books. For example, Jiang and Katsamakas [30] explore the impact of the entry of an e-book seller on the strategic interaction in book markets and conclude that the market asymmetries, ownership of ebook sellers, and readers' preferences for e-books affect the prices, market shares, and total book readership. In analyzing publishers' channel selection, Hua et al. [31] find that the wholesale of p-book and reader acceptance of e-book affect the channel selection of publishers. Both studies do not consider the cooperation contract and profit division between the publisher and the retailers after the entry of e-books. The main contribution of our paper is that we study the two pricing models widely used in the book industry: wholesale and agency model pricing. Subsequently, we compare the different price equilibriums when considering the competition between the two forms of books.

Our primary findings are as follows. The prices of the two book forms are lower under the agency pricing model than those under the traditional wholesale model; the agency pricing model benefits the whole system and the publishers 
when the degree of substitutability is not very high; the readers' preference toward e-books, the degree of substitution between the two forms of books, and the ownership of the ebooks seller dictate how much the profit of the whole system and the publisher may increase.

The remainder of this paper is organized as follows. Section 2 introduces the basic model. Section 3 provides an analysis of the equilibrium outcome under the two different pricing models. Section 4 studies the impact of the parameters. Finally, Section 5 provides the conclusion and offers some directions for future works.

\section{Model Formulation and Notations}

To address the questions stated above, we construct a model with a publisher who simultaneously publishes both conventional paper books and e-books and two book retailers who retail p-books and e-books (Figure 1). Let $q_{T}$ and $q_{e}$ denote the demand for p-books and e-books when their prices are at $p_{T}$ and $p_{e}$, respectively. $c_{T}$ denotes the p-books' production cost, and $g_{T}$ and $g_{e}$ denote the profits of the $\mathrm{p}$ book retailers and e-book retailers, respectively. We assume a linear downward sloping demand function. We utilize the demand function given by McGuire and Staelin [32] as follows:

$$
\begin{gathered}
q_{T}=\mu S\left(1-\frac{\beta}{1-\theta} p_{T}+\frac{\beta \theta}{1-\theta} p_{e}\right), \\
q_{e}=(1-\mu) S\left(1+\frac{\beta \theta}{1-\theta} p_{T}-\frac{\beta}{1-\theta} p_{e}\right),
\end{gathered}
$$

where $0 \leq \mu \leq 1,0 \leq \theta<1$, and $\beta$ and $S$ are positive.

The constant $S$ is a scale factor equal to the total demand for conventional books and e-books or market potential. The parameters $\mu$ and $\theta$ represent two different aspects: the absolute difference in demand and the substitutability of the two different forms of books. The parameter $\mu$ denotes the market share for conventional books caused by the readers' e-book acceptance, that is, the absolute difference in demand. When prices are equal, the ratio of the quantities of these two forms of books is $\mu /(1-\mu)$. Changes in $\mu$ show the different preferences for different forms of books. Many factors influence the preference for e-books such as switching costs (Huang and Hsieh [29]) and the subject of the titles [33], among others $[34,35]$. In contrast, the parameter $\theta$ affects the substitutability of the two forms of books. In our case, $\theta$ captures the extent to which e-book sales cannibalize the conventional paper books sales, which may be related to the type of readers and the subject of the titles. Parameters $\beta$ and $\theta$ provide information on the own-price and cross-price elasticity, respectively.

To guarantee that the quantities of the books are nonnegative, the above model also has the following constraints: $\theta /(1+\theta) \leq \mu \leq 1 /(1+\theta)$ and $c_{T} \beta \leq 1$. McGuire and Staelin [32] provide the derivation of the conditions. These constraints show that the market share of the p-books should be small or large enough to assure the existence of two forms of books in the market.
We consider two prevalent pricing strategies in the book industry: wholesale and agency pricing. Under the wholesale pricing strategy, the retailer makes its pricing decision after the publisher provides the wholesale prices of the books. Under the agency pricing strategy, the publisher has control over the e-book price, and the retailer just reserves partial revenue after paying the most part to the publisher. To capture the difference between the two pricing models, we then consider the results when all participants make decisions as a whole system.

Here, we use the Stackelberg model to analyze the equilibrium, similar to the analyses of other researchers. We assume that the publisher will make its decision as a Stackelberg leader under different pricing strategies.

\section{Price Equilibriums under Different Pricing Models}

3.1. Under the Wholesale Pricing Model (Wholesale Pricing, $W P)$. Based on the wholesale prices of books under the wholesale pricing model, the conventional bookseller and the e-book seller choose their retail prices, maximizing their own independent profits. The profit functions of the retailers are

$$
\begin{gathered}
g_{T}=\mu S\left(1-\frac{\beta}{1-\theta} p_{T}+\frac{\beta \theta}{1-\theta} p_{e}\right)\left(p_{T}-w_{T}\right), \\
g_{e}=(1-\mu) S\left(1+\frac{\beta \theta}{1-\theta} p_{T}-\frac{\beta}{1-\theta} p_{e}\right)\left(p_{e}-w_{e}\right) .
\end{gathered}
$$

This problem is similar to the ones studied by MaGuire and Staelin [32] and Huang and Swaminathan [17], whose studies give a Nash equilibrium. The retailers' reaction functions with optimal prices are given by

$$
\begin{aligned}
& p_{T}^{*}=\frac{-2\left(1+\beta w_{T}\right)+\theta(1+\theta)-\beta \theta w_{e}}{\beta\left(-4+\theta^{2}\right)}, \\
& p_{e}^{*}=\frac{-2\left(1+\beta w_{e}\right)+\theta(1+\theta)-\theta \beta w_{T}}{\beta\left(-4+\theta^{2}\right)} .
\end{aligned}
$$

We can obtain the concavity as follows: the optimal prices of the two forms of books in the Nash equilibrium are concave decreasing functions with respect to $\theta$, which is the substitutability factor between the two forms of books (as the first-order conditions are given by $d p_{T}^{*} / d \theta=-\left(\left(4+\theta^{2}\right)(1-\right.$ $\left.\left.\beta w_{e}\right)+4 \theta\right) / \beta\left(4-\theta^{2}\right)^{2}<0, d p_{e}^{*} / d \theta=-\left(\left(4+\theta^{2}\right)\left(1-\beta w_{T}\right)+\right.$ $4 \theta) / \beta\left(4-\theta^{2}\right)^{2}<0$. Given the reaction functions, we can derive the publisher's profit function:

$$
\begin{aligned}
g_{p}= & \mu S\left(1-\frac{\beta}{1-\theta} \frac{-2\left(1+\beta w_{T}\right)+\theta(1+\theta)-\beta \theta w_{e}}{\beta\left(-4+\theta^{2}\right)}\right. \\
& \left.\quad+\frac{\beta \theta}{1-\theta} \frac{-2\left(1+\beta w_{e}\right)+\theta(1+\theta)-\theta \beta w_{T}}{\beta\left(-4+\theta^{2}\right)}\right) \\
& \times\left(w_{T}-c_{T}\right)+(1-\mu) S \\
& \times\left(1+\frac{\beta \theta}{1-\theta} \frac{-2\left(1+\beta w_{T}\right)+\theta(1+\theta)-\beta \theta w_{e}}{\beta\left(-4+\theta^{2}\right)}\right. \\
& \left.\quad-\frac{\beta}{1-\theta} \frac{-2\left(1+\beta w_{e}\right)+\theta(1+\theta)-\theta \beta w_{T}}{\beta\left(-4+\theta^{2}\right)}\right) w_{e}-F .
\end{aligned}
$$




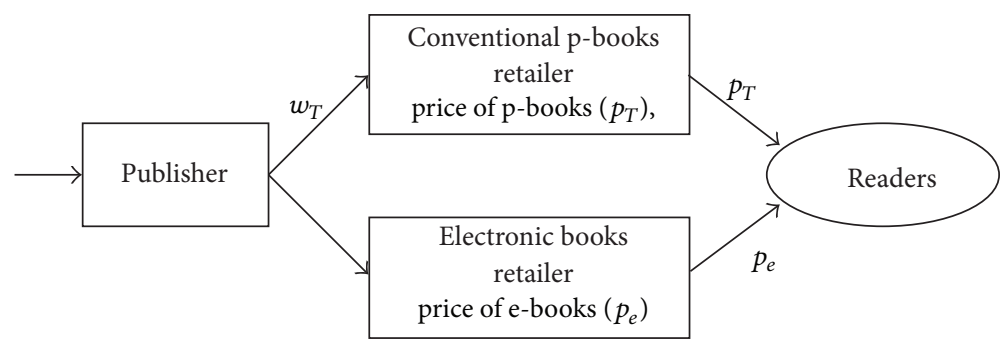

FIGURE 1: Dual channels of the book industry. The publisher provides two forms of books to the retailers. And the p-books are sold under the price-only contract, and the wholesale price and retail price of p-books are $w_{T}$ and $p_{T}$ respectively. The e-books can be sold either under wholesale pricing model or under agency pricing model.

In (4), $F$ denotes the fixed cost of the e-books. The publisher will make its wholesale price decision by maximizing the profit, and thus we obtain the wholesale price of the books. Substituting the optimal wholesale prices, we can obtain the optimal wholesale prices and retail prices in the following proposition (all proofs are in the Appendix).

Proposition 1. The optimal wholesale prices and the retail prices of books under the wholesale pricing model are given by

$$
\begin{aligned}
w_{T}^{1 *}= & -2 \mu(1-\mu)\left(1+\beta c_{T}\right)\left(2-\theta^{2}\right)^{2}+u \theta^{2} \beta c_{T} \\
& \left.+2 \mu(1-\mu) \theta\left(2-\theta^{2}\right)-(1-\mu) \theta(1-\theta)(2+\theta)\right) \\
& \times\left(-4 \mu \beta(1-\mu)\left(2-\theta^{2}\right)^{2}+\beta \theta^{2}\right)^{-1}, \\
w_{e}^{1 *}= & \left(\mu \theta(1-2 \mu)\left(2-\theta^{2}\right)\left(1-\beta c_{T}\right)\right. \\
& \left.-2 \mu(1-\mu)\left(2-\theta^{2}\right)^{2}+\mu \theta^{2}\right) \\
& \times\left(-4 \mu \beta(1-\mu)\left(2-\theta^{2}\right)^{2}+\beta \theta^{2}\right)^{-1}, \\
p_{T}^{1 *}= & \left(2 \mu(1-\mu)\left(-2+\theta^{2}\right)\left((1-\theta)(2 \theta+3)+\beta c_{T}\right)\right. \\
& \left.+(1-\mu) \theta(\theta-1)+\mu \theta^{2} \beta c_{T}\right) \\
\times & \left(4 \mu(1-\mu) \beta\left(-4+4 \theta^{2}-\theta^{4}\right)+\beta \theta^{2}\right)^{-1}, \\
p_{e}^{1 *}= & \left(2 \mu(1-\mu)\left(-2+\theta^{2}\right)\left((1-\theta)(2 \theta+3)+\theta \beta c_{T}\right)\right. \\
& \left.+\mu \theta\left(\beta c_{T}+\theta-1\right)\right) \\
\times & \left(4 \mu(1-\mu) \beta\left(-4+4 \theta^{2}-\theta^{4}\right)+\beta \theta^{2}\right)^{-1} .
\end{aligned}
$$

Lemma 2. If the demand is symmetric in the book industry (i.e., $\mu=1 / 2$ ), the prices of books can be rewritten as follows:

$$
\begin{aligned}
& p_{T}^{1 *} \\
& =\frac{\left(2-\theta^{2}\right)\left((1-\theta)(2 \theta+3)+\beta c_{T}\right)+\theta(1-\theta)-\theta^{2} \beta c_{T}}{2 \beta\left(4-\theta^{2}\right)\left(1-\theta^{2}\right)} \\
& p_{e}^{1 *} \\
& =\frac{\left(2-\theta^{2}\right)\left((1-\theta)(2 \theta+3)+\theta \beta c_{T}\right)+\theta\left(1-\theta-\beta c_{T}\right)}{2 \beta\left(4-\theta^{2}\right)\left(1-\theta^{2}\right)}
\end{aligned}
$$

Moreover, both prices of the books will decrease as the degree of substitutability increases.

Lemma 2 shows that when the degree of substitutability of the two forms of books increases, the competition between the retailers will be fiercer, and consequently the retailers will lower the prices of books to attract more readers.

3.2. Under the Agency Pricing Strategy (Agency Pricing, $A P)$. Under the agency pricing strategy, the publisher will price the e-books, and the e-book retailer will receive the rest of the revenue after giving a portion to the publisher. The conventional book retailers will price the $\mathrm{p}$ books to maximize their profit after the publisher gives the wholesale price of the $\mathrm{p}$-books and the retail price of the e-books. If the e-book retailer is independent, the profit function of the conventional p-books retailer is as follows:

$$
g_{T}=\mu S\left(1-\frac{\beta}{1-\theta} p_{T}+\frac{\beta \theta}{1-\theta} p_{e}\right)\left(p_{T}-w_{T}\right) .
$$

From the first order condition, we can obtain the price reaction function of the $\mathrm{p}$-books retailer as follows:

$$
p_{T}^{*}=\frac{(1-\theta)+\beta\left(w_{T}+\theta p_{e}\right)}{2 \beta} .
$$

As for the e-book retailer, the publisher decides on the price of the e-book, and thus the retailer only needs to bargain with the publisher on how much proportion of the revenue he/she should pay the publisher. We suppose that $\alpha$ denotes the proportion the e-book retailer should give to the publisher. In the agency pricing model, it is usually set at 0.7 in practice. Therefore, we can obtain the profit function of the publisher:

$$
\begin{aligned}
g_{p}= & \mu S\left(1-\frac{\beta}{1-\theta} \frac{(1-\theta)+\beta\left(w_{T}+\theta p_{e}\right)}{2 \beta}+\frac{\beta \theta}{1-\theta} p_{e}\right) \\
& \times\left(w_{T}-c_{T}\right)+(1-\mu) S \\
& \times\left(1+\frac{\beta \theta}{1-\theta} \frac{(1-\theta)+\beta\left(w_{T}+\theta p_{e}\right)}{2 \beta}-\frac{\beta}{1-\theta} p_{e}\right) p_{e}^{\alpha-F .}
\end{aligned}
$$


From the first- and the second-order conditions, we can conclude that when $\alpha \mu(1-\mu)\left(-8+\theta^{2}(6-\alpha)\right)+\theta^{2}\left(\alpha^{2}(1-\right.$ $\left.\mu)+\mu^{2}\right)<0$, the total profit of the publisher is concave with respect to $w_{T}$ and $p_{e}$. We can also derive the optimal wholesale price of the $\mathrm{p}$-books and the retail price of e-books in Proposition 3.

Proposition 3. When the agency pricing strategy is adopted, the wholesale prices of p-books and the retail price of books are given by

$$
\begin{gathered}
w_{T}^{2 *}=\left(\alpha \mu ( 1 - \mu ) \left(\left(1+\beta c_{T}\right)\left(-4+3 \theta^{2}\right)\right.\right. \\
\left.+\theta\left(2-\alpha \theta+2 \alpha-\theta^{2}-\alpha \theta^{2}\right)\right) \\
\left.+\alpha^{2}(1-\mu) \theta(\theta+2)(\theta-1)+\mu^{2} \theta^{2} \beta c_{T}\right) \\
\times\left(\mu(1-\mu) \alpha \beta\left(6 \theta^{2}-8-\alpha \theta^{2}\right)\right. \\
\left.+\alpha^{2} \theta^{2} \beta(1-\mu)+\mu^{2} \theta^{2} \beta\right)^{-1}, \\
p_{e}^{2 *}=\frac{\alpha \mu(\mu-1)\left(4+\theta \beta c_{T}-3 \theta^{2}-\theta\right)-\mu^{2} \theta\left(1-\theta-\beta c_{T}\right)}{\mu(1-\mu) \alpha \beta\left(6 \theta^{2}-8-\alpha \theta^{2}\right)+\alpha^{2} \theta^{2} \beta(1-\mu)+\mu^{2} \theta^{2} \beta}, \\
p_{T}^{2 *}=\left(\alpha \mu ( 1 - \mu ) \left(\beta c_{T}\left(-2+\theta^{2}\right)-\left(6-3 \theta-5 \theta^{2}+2 \theta^{3}\right)\right.\right. \\
+\alpha \theta(1-\theta)) \\
\left.-\alpha^{2}(1-\mu) \theta(1-\theta)+\mu^{2} \theta^{2} \beta c_{T}\right) \\
\times\left(\mu(1-\mu) \alpha \beta\left(6 \theta^{2}-8-\alpha \theta^{2}\right)\right. \\
\left.+\alpha^{2} \theta^{2} \beta(1-\mu)+\mu^{2} \theta^{2} \beta\right)^{-1} .
\end{gathered}
$$

If the demand is symmetric in the book industry (i.e., $\mu=$ $1 / 2$ ), the prices of books can be rewritten as follows:

$$
\begin{gathered}
p_{e}^{2 *}=\frac{-4 \alpha+\alpha \theta\left(1-\beta c_{T}\right)+\alpha\left(3 \theta^{2}+\theta\right)-\theta+\theta^{2}}{\left(\alpha \theta^{2}(6+\alpha)-8 \alpha+\theta^{2}\right) \beta} \\
p_{T}^{2 *}=\left(\beta c_{T}\left(-2 \alpha+\alpha \theta^{2}+\theta^{2}\right)-6 \alpha+3 \alpha \theta\right. \\
\left.+5 \alpha \theta^{2}-2 \alpha \theta^{3}-\alpha^{2} \theta+\alpha^{2} \theta^{2}\right) \\
\times\left(\left(\alpha \theta^{2}(6+\alpha)-8 \alpha+\theta^{2}\right) \beta\right)^{-1}
\end{gathered}
$$

Consequently, we can analyze the change in price equilibriums when the substitutability between the two forms of books increases. First, we consider the situation in which $\theta=$ 0 ; that is, the two forms of books are independent. The factors that may affect the prices and the profit distribution between the participants are the cost of $\mathrm{p}$-books and their own price elasticity. Table 1 gives the prices of books and profit when ebooks and p-books are independent.

Based on Table 1, we can conclude that the prices of $\mathrm{p}$ books is equal under both wholesale pricing and agency pricing models. The price of e-books are higher under the wholesale pricing model, and the publisher gains more profit under the agency pricing model. Moreover, the total profit of the whole system is higher under the agency pricing model than under the wholesale pricing model when $\alpha>0.5$.

Compare the previous prices under different pricing models, and then we can find which pricing strategy will benefit the readers most. To better understand the results, we use numerical analyses. Figure 2 presents the information on how the prices of books change when the substitutability grows. We demonstrate that the result still holds when the parameter changes in Section 4. Moreover, we can see that the prices of both books are lower under the agency pricing model.

Lemma 4. Given that the demand is symmetric (i.e., $\mu=1 / 2$ ) and $\alpha=0.7$, the prices of p-books and e-books have the following characteristics.

(a) The prices of p-books under the agency model are lower than those under the wholesale pricing model.

(b) The prices of e-books under the agency are lower model than those under the wholesale pricing model.

When the publisher provides an agency pricing contract for the retailers, its goal is to relieve the competition between e-books and p-books. In fact, the agency pricing model cannot help to achieve the initial goal. The prices of p-books are lower under the agency model than under the wholesale model. The prices of e-books are lower under the agency pricing model than under the wholesale pricing model, which is counterintuitive. Some people may argue that when the publisher and Apple set prices using the agency model, the price of the e-book is actually higher than that given by Amazon.

Indeed, it is not the pricing model that helps increase the prices but the publishers themselves who want to raise the prices. Their possible reasons for doing so are as follows. First, the rationale behind Amazon's move to engage in the aggressive discounting of e-books was to stimulate greater interest in its e-book reader, the Kindle. This paper ignores the sales of e-book readers, and we refer the reader to the analyses by $\mathrm{Yu}$ et al. [36] on the pricing issue when considering the ebook reader. Second, increasing the price of e-books is not wise for the publisher. In fact, increasing the prices of e-books will compel more and more readers to choose to buy p-books. Consequently, the publishers may gain less profit because of the p-books' higher cost disadvantage. Finally, increasing the prices will not relieve the degree of canalization, and in the end, the agency pricing model will bring the readers lower prices of e-books. To summarize, the readers' fear that the prices of e-books will increase after the agency pricing model is adopted appears to be misguided.

Lemma 5. Given that the demand is symmetric (i.e., $\mu=1 / 2$ ) and $\alpha=0.7$, the publishers have a higher incentive to adopt the agency model when the degree of substitutability is not very high because this model can bring more profits for the publisher.

Figure 3 shows how the profit of the publisher under two different pricing models changes when the substitutability 
TABLE 1: Prices of books and profit distribution when e-books and p-books are independent.

\begin{tabular}{lcc}
\hline & $\mathrm{WP}$ & $\mathrm{AP}$ \\
\hline$p_{T}^{*}$ & $\left(3+\beta c_{T}\right) /(4 \beta)$ & $\left(3+\beta c_{T}\right) /(4 \beta)$ \\
$p_{e}^{*}$ & $3 /(4 \beta)$ & $1 /(2 \beta)$ \\
\hline$g_{T}^{*}$ & $\mu S\left(1-\beta c_{T}\right)^{2} /(16 \beta)$ & $\mu S\left(1-\beta c_{T}\right)^{2} /(16 \beta)$ \\
$g_{e}^{*}$ & $(1-\mu) S /(16 \beta)$ & $(1-\alpha)(1-\mu) S /(4 \beta)$ \\
$g_{p}^{*}$ & $S\left(\mu\left(1-\beta c_{T}\right)^{2}+1-\mu\right) /(8 \beta)$ & $S\left(\mu\left(1-\beta c_{T}\right)^{2}+2 \alpha(1-\mu)\right) /(8 \beta)$ \\
\hline Total & $3 S\left(\mu\left(1-\beta c_{T}\right)^{2}+1-\mu\right) /(16 \beta)$ & $S\left(3 \mu\left(1-\beta c_{T}\right)^{2}+(1+3 \alpha)(1-\mu)\right) /(16 \beta)$ \\
\hline
\end{tabular}

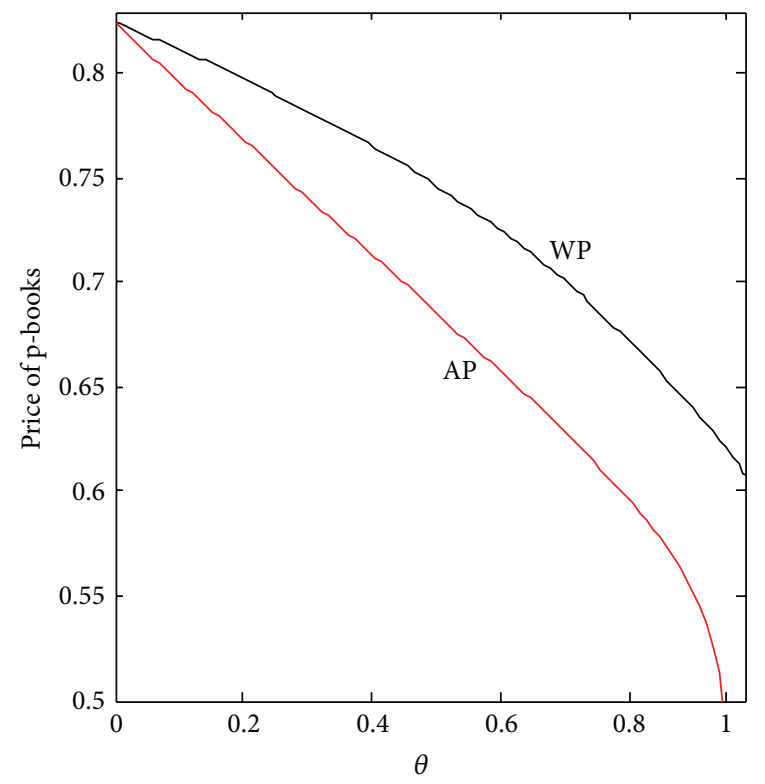

(a)

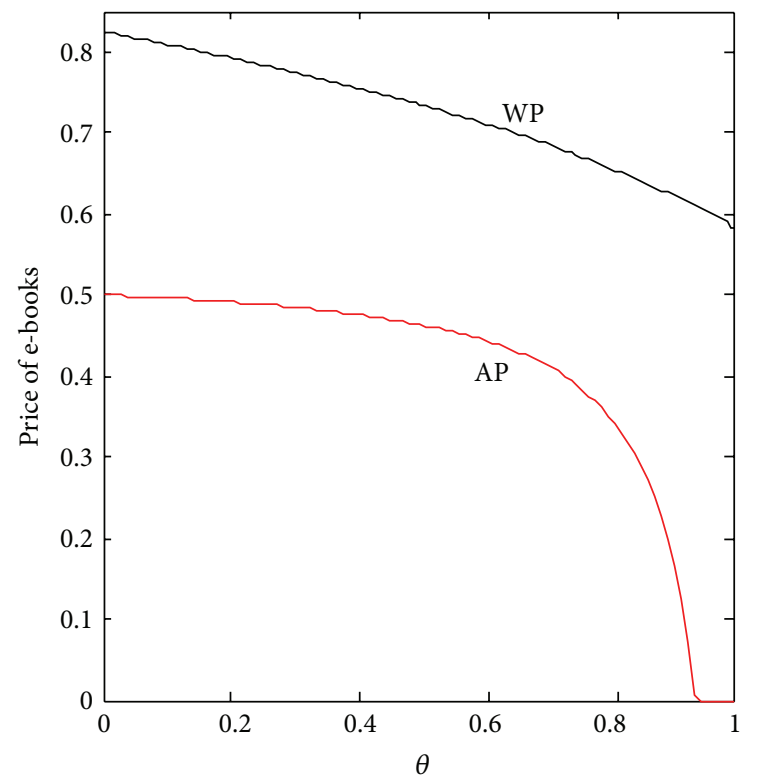

(b)

FIGURE 2: Comparison of retail prices of books under different pricing strategies. (a) Information of the retail price of p-books and (b) the e-books' retail prices. And the prices under wholesale pricing are marked by black and by red under agency pricing model. Here, we set $\beta=1$, and $c_{T}=0.3$, without loss of generality. We can see that in both cases, the retail prices are lower under agency pricing model.

grows. The e-book sales can canalize the conventional book sales as more readers start to prefer e-books to conventional p-books. However, the pricing model does not help reduce the canalization effect but only slows down the readers' acceptance of e-books. The agency model can generate more profit for the whole system because it also benefits the readers by providing lower-priced books when the degree of substitutability is not very high. Thus, the publishers have higher incentives to adopt the agency pricing model than the wholesale pricing model. This conclusion is consistent with the practical evidence that some publishers switch to agency pricing to deal with Amazon after introducing this pricing strategy to Apple.

3.3. When All Participants Make Decisions as a Whole System (Integrated Pricing, IP). For the whole system consisting of a publisher and two book retailers, the decisions which should be made are the retail prices of the books. Given the retail prices of the books, we can obtain the total profit as follows:

$$
\begin{aligned}
\text { Total }= & \mu S\left(1-\frac{\beta}{1-\theta} p_{T}+\frac{\beta \theta}{1-\theta} p_{e}\right)\left(p_{T}-c_{T}\right) \\
& +(1-\mu) S\left(1+\frac{\beta \theta}{1-\theta} p_{T}-\frac{\beta}{1-\theta} p_{e}\right) p_{e}-F
\end{aligned}
$$

Form the first- and second-order conditions, we can conclude that when $\theta^{2}-4 \mu+4 \mu^{2}<0$, the total profit of the whole system is concave with respect to $p_{T}$ and $p_{e}$. To maximize the total profit of the whole system, we can obtain the optimal price of the books given by Proposition 6 . 


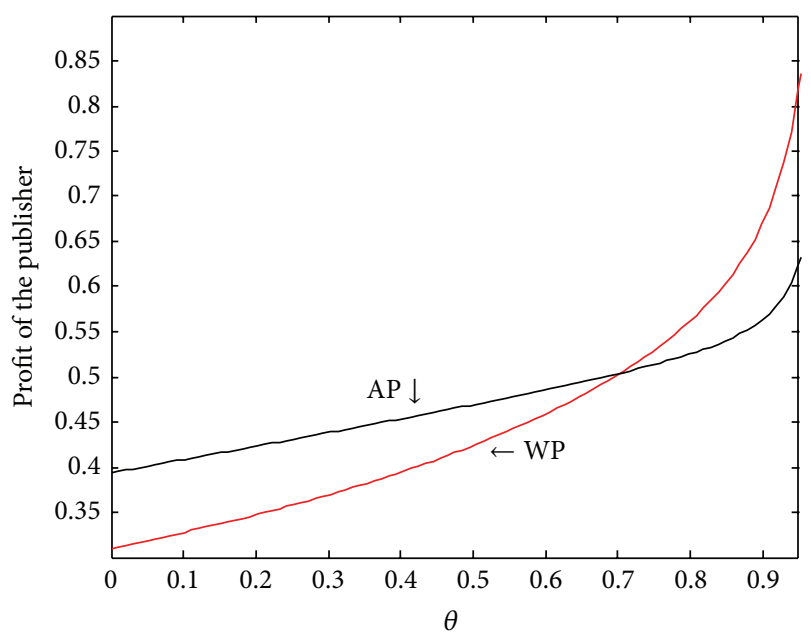

FIGURE 3: Comparison of the publisher's profits under different pricing strategies. The prices under wholesale pricing model are marked by black and the prices under agency pricing model are marked by red. We can see that the profit of the publisher is lower under wholesale pricing model when the substitutability is low.

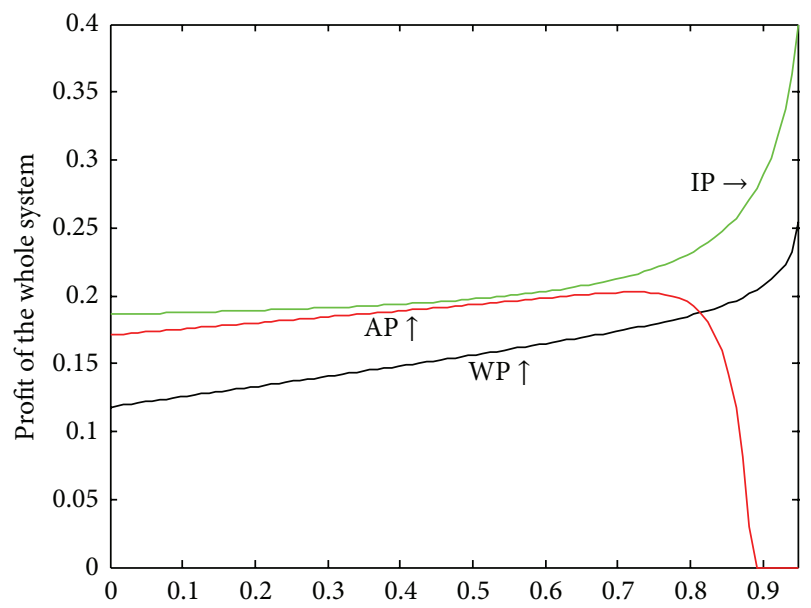

FIGURE 4: Comparison of the total profit of the whole system under different pricing strategies. The profits of the whole system are marked by green when the participants make decision as a whole system, by red when the agency pricing strategy is adopted, and by black when under wholesale pricing model.

Proposition 6. When all participants make decisions as a whole system, the prices of p-books and e-books are given by

$$
\begin{gathered}
p_{T}^{3 *} \\
=-\frac{2 \mu(1-\mu)\left(1+\beta c_{T}-\theta\right)+\theta(1-\theta)(1-\mu)-\mu \theta^{2} \beta c_{T}}{\beta\left(\theta^{2}-4 \mu+4 \mu^{2}\right)}, \\
p_{e}^{3 *}=\frac{\mu\left((1-2 \mu) \theta\left(1-\beta c_{T}\right)-2(1-\mu)+\theta^{2}\right)}{\beta\left(\theta^{2}-4 \mu+4 \mu^{2}\right)} .
\end{gathered}
$$

To clearly demonstrate the difference the two pricing strategies, we study the circumstance when the demand is symmetric. The prices are given by the following when $\mu=$ $1 / 2$ :

$$
\begin{gathered}
p_{T}^{3 *}=\frac{1+\beta c_{T}}{2 \beta}, \\
p_{e}^{3 *}=\frac{1}{2 \beta} .
\end{gathered}
$$

Thus, we can derive the profit of the whole system and the publisher as follows:

$$
\text { Total }^{*}=\frac{S\left(2(1-\theta)\left(1-\beta c_{T}\right)+\beta^{2} c_{T}^{2}\right)}{8 \beta(1-\theta)}-F .
$$

To better understand the supply chain's efficiency, we then compare the profits of the whole system under different cases. Figure 4 provides information on how the profits of the whole system change when the substitutability changes. Given that the changes in parameters $F$ and $S$ do not affect the results, we set $S=1$ and $F=0$ to simplify the results.

Lemma 7. Given that the demand is symmetric (i.e., $\mu=1 / 2$ ) and $\alpha=0.7$, the total profit of the whole system is higher under the agency pricing model than under the wholesale pricing model when the substitutability is not very high.

We can conclude from Figure 4 that the agency policy can help increase the revenues for the whole system when the degree of substitutability is not very high. When the degree of substitutability increases to some extent, the revenue of the whole system under the agency pricing model may decrease because the best decision for the publisher to gain more profit is to sell e-books only.

\section{Impact of Different Parameters and Managerial Insights}

Based on the results above, we examine the impact of different reader preferences, price elasticity, and the autonomy of the e-book retailers on price equilibriums.

4.1. Impact of Demand Preferences. We now conduct a numerical study to better understand the impact of the parameters on the results. Note that parameter $\mu$ represents the market share of conventional paper books. When more readers begin to use e-books instead of p-books, the level of $\mu$ will be lower than before. Figure 5 shows the impact of demand preference on the price of books.

When more readers start to use e-books, the prices of $\mathrm{p}$ books increase and the prices of e-books decrease (as shown in Figure 5). This observation is consistent with the results reported by Jiang and Katsamakas [30] that the prices in the book market may increase after the entry of e-books. Thus, the result that the prices of the two forms of books are lower under the agency pricing model still holds. 


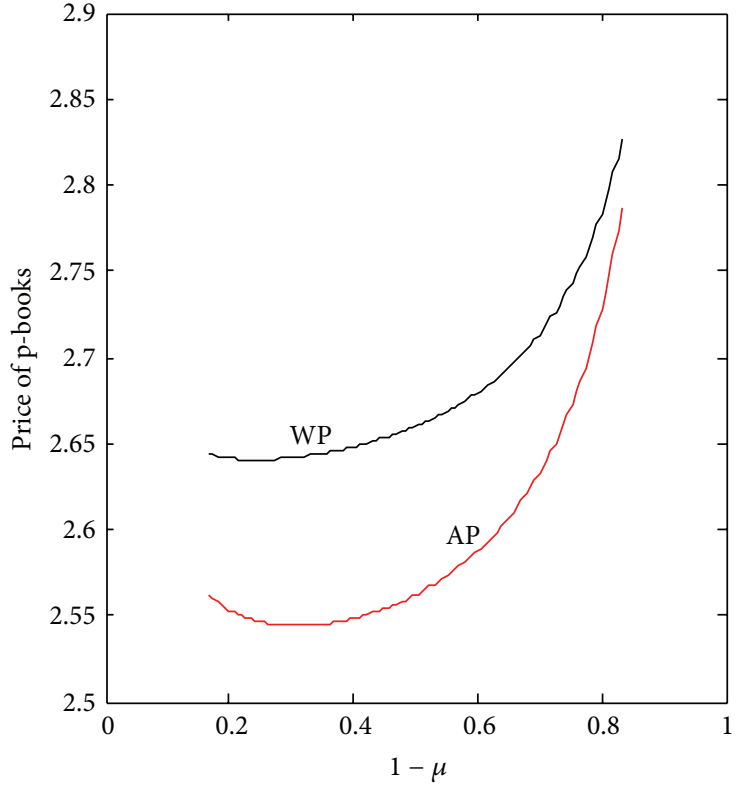

(a)

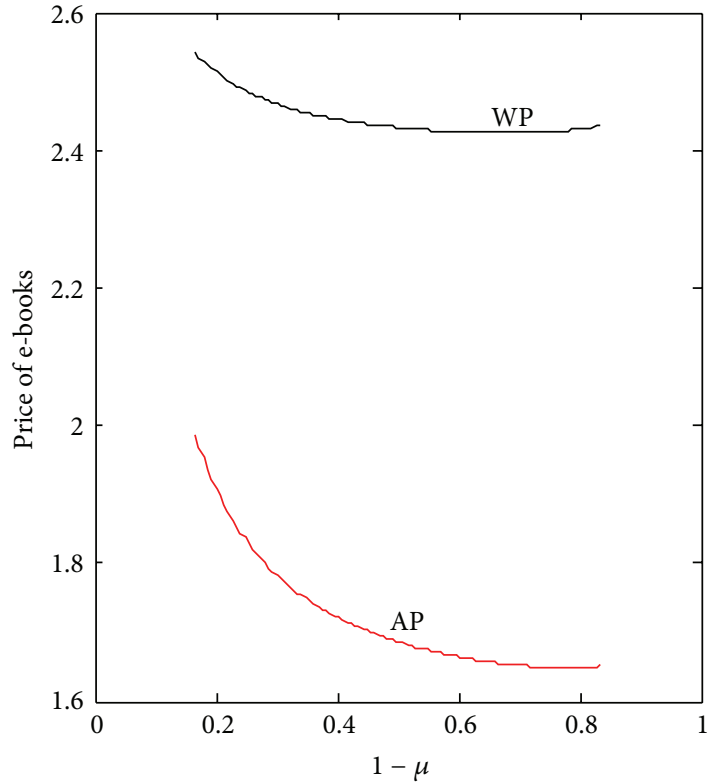

(b)

Figure 5: Retail price of p-books and e-books. Here, we set $\beta=0.3, \alpha=0.7, c_{T}=1$, and $\theta=0.2, S=1$. (a) Retail prices of p-books and (b) is for retail prices of e-books. We can see that when the potential demand market changes, the result that both prices of the books are lower under agency pricing model will still hold.

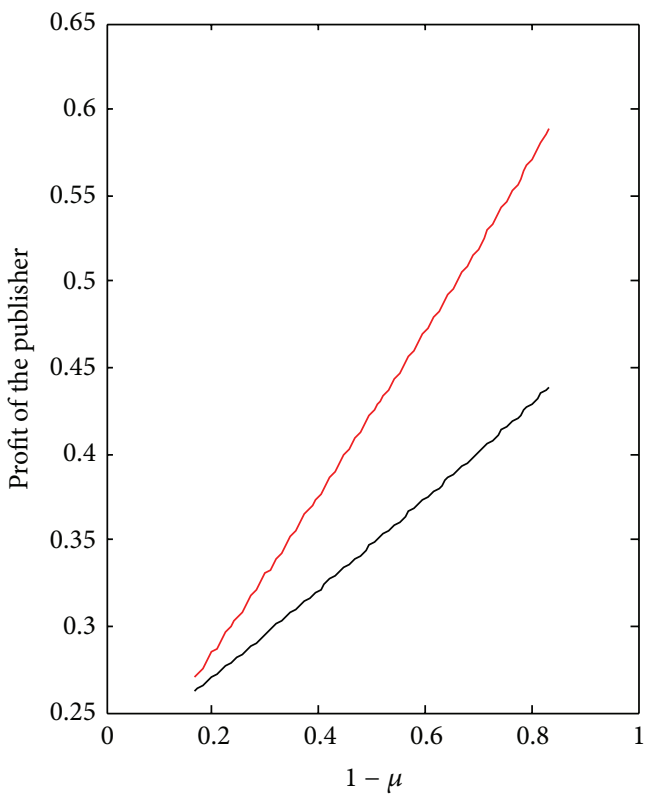

(a)

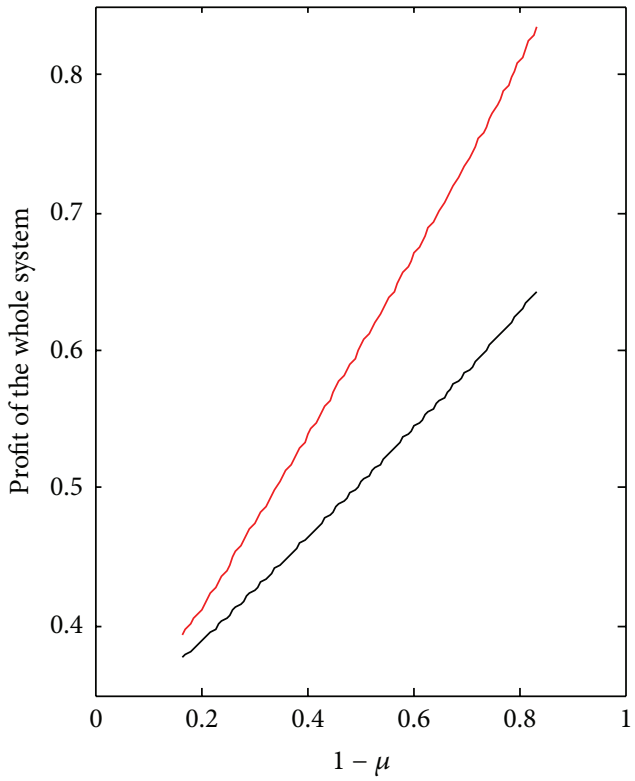

(b)

Figure 6: Profit of the publisher and the whole system when the potential demand changes. Here, we set $\beta=0.3, \alpha=0.7, c_{T}=1, \theta=0.2$, and $S=1$. (a) Profit of the publisher and (b) the profit of the whole system. We can see that when the potential demand market changes, the result that agency pricing model benefits the whole system and the publisher still holds.

The total profit of the whole system and the publisher increases (as shown in Figure 6) as more readers accept the e-books because of the e-books' lower cost advantage.

4.2. Impact of Price Elasticity. The agency pricing strategy can generate more profits for the whole system.
As price elasticity increases, the reader becomes more sensitive to the changes in prices (as shown in Figure 7). To attract more readers, the participants will price the books at a lower level. The prices of books are expected to decrease as price elasticity increases. 


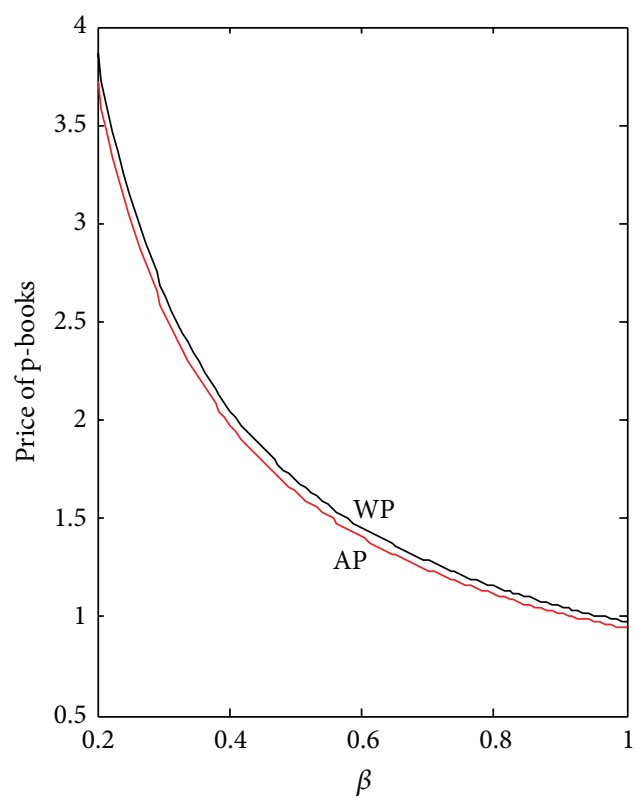

(a)

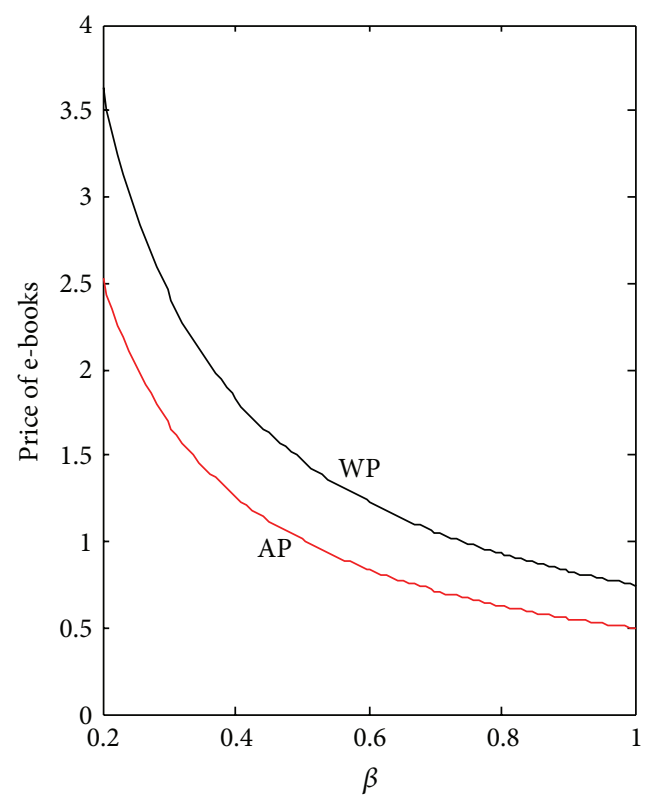

(b)

Figure 7: Price of books when the price elasticity changes. Here, we $\operatorname{set} \theta=0.2, \alpha=0.7, c_{T}=1, \mu=0.5$, and $S=1$. (a) Retail prices of p-books and (b) retail prices of e-books. We can see that when the price elasticity changes, the results that both prices of the books will be lower under agency pricing model still hold.

The profit of the whole system and the publisher is expected to decrease as price elasticity increases because the competition becomes fiercer when the retailers use the price to attract readers (Figure 8). Furthermore, the results in Section 3 still hold when the price elasticity changes.

4.3. Impact of the Autonomy of e-Book Retailers. In this section, we consider the situation in which the e-book seller joins the physical book retailer. First, we consider the results under the wholesale pricing model.

4.3.1. Under the Wholesale Pricing Strategy. When the ebook seller is owned by the p-book retailer, only two players exist in this game. Given the wholesale prices of the books, the bookseller will make his/her pricing decision to maximize the total profit of conventional books and ebooks. The whole profit function of the book retailer is as follows:

$$
\begin{aligned}
g_{T}+g_{e}= & \mu S\left(1-\frac{\beta}{1-\theta} p_{T}+\frac{\beta \theta}{1-\theta} p_{e}\right)\left(p_{T}-w_{T}\right) \\
& +(1-\mu) S\left(1+\frac{\beta \theta}{1-\theta} p_{T}-\frac{\beta}{1-\theta} p_{e}\right)\left(p_{e}-w_{e}\right)
\end{aligned}
$$

When $-4 \mu+4 \mu^{2}+\theta^{2}<0$, the total profit of the whole retailer is concave with respect to $p_{T}$ and $p_{e}$. Given that $\theta /(1+$ $\theta) \leq \mu \leq 1 /(1+\theta)$, we can see that the previous inequality holds. Thus, we can obtain the optimal price functions of the p-books and e-books:

$$
\begin{aligned}
p_{T}^{*}=( & 2 \mu\left(1+w_{T} \beta\right)(\mu-1)-\left(1-w_{e} \beta\right) \theta(2 \mu-1)(\mu-1) \\
+ & \left.\theta^{2}\left(1-\mu+\mu w_{T} \beta\right)\right) \times\left(\beta\left(-4 \mu+4 \mu^{2}+\theta^{2}\right)\right)^{-1}, \\
p_{e}^{*}=( & 2 \mu\left(1+w_{e}\right)(\mu-1)+\mu\left(1-w_{T} \beta\right) \theta(1-2 \mu) \\
+ & \left.\theta^{2}\left(w_{e} \beta+\mu-\mu w_{e} \beta\right)\right) \times\left(\beta\left(-4 \mu+4 \mu^{2}+\theta^{2}\right)\right)^{-1} .
\end{aligned}
$$

Given the reaction function of the retailer, we can derive the publisher's profit function:

$$
\begin{aligned}
g_{p}= & \mu S\left(1-\frac{\beta}{1-\theta} p_{T}^{*}+\frac{\beta \theta}{1-\theta} p_{e}^{*}\right)\left(w_{T}-c_{T}\right) \\
& +(1-\mu) S\left(1+\frac{\beta \theta}{1-\theta} p_{T}^{*}-\frac{\beta}{1-\theta} p_{e}^{*}\right) w_{e}-F .
\end{aligned}
$$

The publisher will make its decision to maximize profit. We can obtain the wholesale price of the books as follows:

$$
\begin{gathered}
w_{T}^{*}=\frac{\beta c_{T}+1}{2 \beta}, \\
w_{e}^{*}=\frac{1}{2 \beta} .
\end{gathered}
$$

Proposition 8. When the e-book retailer is integrated with the p-book retailer, the publisher will set the wholesale price only 


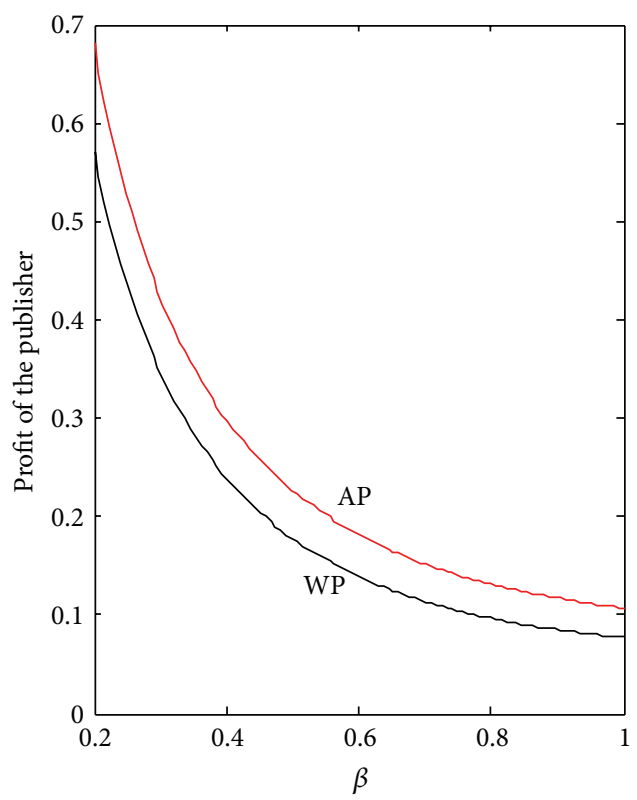

(a)

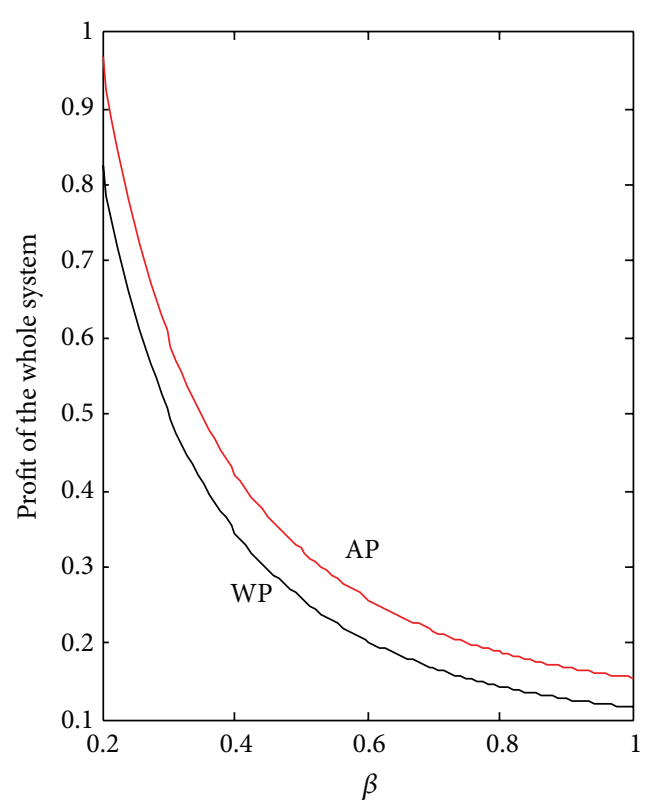

(b)

Figure 8: Profit of the whole system and the publisher as price elasticity increases. Here, we set $\theta=0.2, \alpha=0.7, c_{T}=1, \mu=0.5$, and $S=1$. (a) Profit of the publisher and (b) the profit of the whole system. We can see that when the price elasticity changes, the result that agency pricing model benefits the whole system and the publisher still hold.

considering the cost of p-books and own-price elasticity under the wholesale pricing model. The retail prices of books are given by

$$
\begin{gathered}
p_{T}^{4 *}=\left(\mu \beta c_{T}\left(\theta^{2}+2 \mu-2\right)-2 \mu(1-\mu)(3-\theta)\right. \\
\left.-(1-\mu)(1-\theta) \theta+\theta^{2}\right) \\
\times\left(2 \beta\left(-4 \mu+4 \mu^{2}+\theta^{2}\right)\right)^{-1}, \\
p_{e}^{4 *}=\frac{6 \mu(\mu-1)-\mu \theta(2 \mu-1)\left(1-\beta c_{T}\right)+(1+\mu) \theta^{2}}{2 \beta\left(-4 \mu+4 \mu^{2}+\theta^{2}\right)} .
\end{gathered}
$$

4.3.2. Under the Agency Pricing Strategy. In this case, the retailer will make the pricing decision of the p-book and the publisher will make the pricing decision of the e-books. The retailer will make his/her decision by maximizing the whole profit of the p-book and e-book sales. The retail's profit function is as follows:

$$
\begin{aligned}
g_{T}+g_{e} \\
=\mu S\left(1-\frac{\beta}{1-\theta} p_{T}+\frac{\beta \theta}{1-\theta} p_{e}\right)\left(p_{T}-w_{T}\right) \\
\quad+(1-\mu) S\left(1+\frac{\beta \theta}{1-\theta} p_{T}-\frac{\beta}{1-\theta} p_{e}\right) p_{e}(1-\alpha) .
\end{aligned}
$$

We can obtain the price reaction function of the retailer as

$$
p_{T}^{*}=\frac{\mu\left(1-\theta+\beta w_{T}\right)+\theta \beta p_{e}(1-\alpha)+\mu \alpha \theta \beta p_{e}}{2 \mu \beta} .
$$

The profit function of the publisher is as follows:

$$
\begin{aligned}
& g_{p} \\
& \begin{aligned}
&=\mu S(1-\frac{\beta}{1-\theta} \frac{\mu\left(1-\theta+\beta w_{T}\right)+\theta \beta p_{e}(1-\alpha)+\mu \alpha \theta \beta p_{e}}{2 \mu \beta} \\
&\left.\quad+\frac{\beta \theta}{1-\theta} p_{e}\right)\left(w_{T}-c_{T}\right)+(1-\mu) S \\
& \times\left(1+\frac{\beta \theta}{1-\theta} \frac{\mu\left(1-\theta+\beta w_{T}\right)+\theta \beta p_{e}(1-\alpha)+\mu \alpha \theta \beta p_{e}}{2 \mu \beta}\right. \\
&\left.\quad-\frac{\beta}{1-\theta} p_{e}\right) p_{e} \alpha-F .
\end{aligned}
\end{aligned}
$$

When $\theta^{2}-4 \mu(1-\mu)\left(\theta^{2}-2 \alpha \theta^{2}+2 \alpha\right)<0$, the total profit of the publisher is concave with respect to $w_{T}$ and $p_{e}$. We can also obtain the optimal wholesale prices of the p-books and the retail price of e-books.

When the e-book retailer joins the p-books retailer, the publisher will make the wholesale price decision on the cost of the p-books, the own-price elasticity, and the market share under the agency pricing model.

The publisher need not be concerned about the market share when making a decision under the wholesale pricing 
model. However, in this case, the publisher considers the market share when making decision.

Proposition 9. When the e-book retailer joins the p-book retailer, the wholesale prices of the p-books and the retail prices of the books are given by

$$
\begin{aligned}
w_{T}^{5 *}=( & \mu(1-\mu)\left(\alpha\left(2 \theta^{3}+2 \theta^{2}-4\right)\right. \\
& \left.+4 \alpha\left(1-\theta^{2}\right)\left(\alpha \theta-\beta c_{T}\right)+2 \theta^{2} \beta c_{T}(\alpha-2)\right) \\
& +\alpha \theta(1-\mu)\left(\left(2-3 \theta^{2}+\theta-\theta \beta c_{T}\right)-4 \alpha\left(1-\theta^{2}\right)\right) \\
& \left.+\theta^{2} \beta c_{T}\right) \times\left(\beta\left(\theta^{2}-4 \mu(1-\mu)\left(\theta^{2}-2 \alpha \theta^{2}+2 \alpha\right)\right)\right)^{-1}, \\
p_{e}^{5 *}= & \left(\mu(1-\mu)\left(4 \alpha\left(-1+\theta^{2}\right)+\theta\left(1-\theta-\beta c_{T}\right)\right)\right. \\
& \left.+\mu^{2} \theta\left(-1+\theta+\beta c_{T}\right)\right) \\
& \times\left(\beta\left(\theta^{2}-4 \mu(1-\mu)\left(\theta^{2}-2 \alpha \theta^{2}+2 \alpha\right)\right)\right)^{-1}, \\
p_{T}^{5 *}=( & -\mu(1-\mu)\left(2 \alpha\left(2 \theta^{3}-3 \theta^{2}-2 \theta+3\right)\right. \\
& \left.\quad-2 \theta^{2}(1+\theta)+\beta c_{T}\left(2 \alpha+\theta^{2}-2 \alpha \theta^{2}\right)\right) \\
& +(1-\mu)\left(5 \theta^{2}+\alpha \theta^{3}-\alpha \theta-\theta^{3}\right)+\mu^{2} \theta^{2}\left(4+\beta c_{T}\right) \\
& \left.-4 \theta^{2}\right) \times\left(\beta\left(\theta^{2}-4 \mu(1-\mu)\left(\theta^{2}-2 \alpha \theta^{2}+2 \alpha\right)\right)\right)^{-1} .
\end{aligned}
$$

In comparing the prices of p-books and e-books under different pricing models, we can see that the autonomy of the e-books retailer does not affect the results.

\section{Conclusion and Future Research Directions}

The emergence of e-books portends significant changes in the book industry, and it forces publishers and retailers to reexamine the pricing strategy of books. In this paper, we assumed a deterministic model to address the demand division between the e-books and p-books, with the demand depending on the prices, degree of substitution, and overall market potential. We use a game theory to determine the price equilibriums and profit distribution under a different pricing model. Through a computational study, we explore the behavior of the publisher and the retailer under different degrees of substitution.

Our results highlight the benefit of adopting the agency pricing strategy. The findings indicate that the agency pricing strategy will provide readers with low-priced books. Our analysis also shows that the agency pricing strategy will help publishers to gain more profit and benefit the whole system when the degree of substitutability is not very high. The agency pricing strategy provides a new recourse division model proved to be effective and efficient. How much the profit of the whole system and the publisher will improve may depend on the readers' preference toward e-books, the degree of substitution between the two forms of books, and the ownership of the e-books seller.
This paper supposes that the demand for books is deterministic, but the demand for a particular book could be uncertain. Our study can be extended by assuming the demand for books as a random variable. For example, future studies could be conducted based on the newsvendor model. The difference in risk sharing under different pricing models could also be explored. Another topic is to consider the dynamic pricing strategy of books.

\section{Appendix}

Proof of Proposition 1. The first-order derivatives of $g_{p}$ with respect to $w_{T}$ and $w_{e}$ are given by

$$
\begin{aligned}
& \quad \frac{\partial g_{p}}{\partial w_{T}}=\frac{\mu\left(2-\theta^{2}\right)\left(\beta c_{T}+1-2 \beta w_{T}\right)-\theta\left(\mu-\beta w_{e}\right)}{(1-\theta)\left(4-\theta^{2}\right)}, \\
& \frac{\partial g_{p}}{\partial w_{e}} \\
& =\frac{(\mu-1)\left(2-\theta^{2}\right)\left(2 \beta w_{e}-1\right)-\theta\left(1-\beta w_{T}\right)+\mu \theta\left(1-\beta c_{T}\right)}{(1-\theta)\left(4-\theta^{2}\right)} .
\end{aligned}
$$

The second-order derivatives of the profit of publisher with respect to the wholesale prices are as follows:

$$
\begin{gathered}
\frac{\partial^{2} g_{p}}{\partial w_{T}^{2}}=\frac{2 \mu \beta\left(\theta^{2}-2\right)}{(1-\theta)\left(4-\theta^{2}\right)}, \\
\frac{\partial^{2} g_{p}}{\partial w_{e}^{2}}=\frac{2(1-\mu) \beta\left(\theta^{2}-2\right)}{(1-\theta)\left(4-\theta^{2}\right)}, \\
\frac{\partial^{2} g_{p}}{\partial w_{T} \partial w_{e}}=\frac{\beta \theta}{(1-\theta)\left(4-\theta^{2}\right)}, \\
\frac{\partial^{2} g_{p}}{\partial w_{T}^{2}} \frac{\partial^{2} g_{p}}{\partial w_{e}^{2}}-\left(\frac{\partial^{2} g_{p}}{\partial w_{T} \partial w_{e}}\right)^{2} \\
=\frac{\beta^{2}\left(4 \mu(1-\mu)\left(\theta^{2}-2\right)^{2}-\theta^{2}\right)}{(1-\theta)^{2}\left(4-\theta^{2}\right)^{2}} .
\end{gathered}
$$

For $\theta /(1+\theta) \leq \mu \leq 1 /(1+\theta)$, then $4 \mu(1-\mu)\left(\theta^{2}-2\right)^{2}-\theta^{2}>0$. Hence, the profit function of the publisher is concave with respect to the prices. We derive the unique equilibrium prices from the first-order conditions as above.

Proof of Lemma 2. Consider

$$
\begin{aligned}
& \frac{d p_{t}^{1 *}}{d \theta}=-\frac{\left(4+\theta^{2}\right)+4 \theta\left(1-\beta c_{T}\right)}{2 \beta\left(4-\theta^{2}\right)^{2}}<0, \\
& \frac{d p_{e}^{1 *}}{d \theta}=-\frac{\left(4+\theta^{2}\right)\left(1-\beta c_{T}\right)+4 \theta}{2 \beta\left(4-\theta^{2}\right)^{2}}<0 .
\end{aligned}
$$


Proof of Proposition 3. The second-order derivatives of the profit of retailer with respect to the retail prices are as follows:

$$
\frac{d^{2} g_{T}}{d p_{T}^{2}}=\frac{-2 \mu S \beta}{1-\theta}<0
$$

And the second-order derivatives of the profit of the publisher with respect to wholesale prices are given by

$$
\begin{aligned}
& \frac{\partial^{2} g_{p}}{\partial w_{T}^{2}} \frac{\partial^{2} g_{p}}{\partial p_{e}^{2}}-\left(\frac{\partial^{2} g_{p}}{\partial w_{T} \partial p_{e}}\right)^{2} \\
& =\frac{-\beta^{2} S^{2}\left(\alpha \mu(1-\mu)\left(-8+\theta^{2}(6-\alpha)\right)+\theta^{2}\left(\alpha^{2}(1-\mu)+\mu^{2}\right)\right)}{4(1-\theta)^{2}} .
\end{aligned}
$$

Proof of Lemma 4. When $\mu=1 / 2$, the prices of the books under wholesale pricing strategy are as follows:

$$
\begin{gathered}
p_{T}^{\mathrm{WP} *}=\frac{\left(2-\theta^{2}\right)(2 \theta+3)+\theta+2 \beta c_{T}(1+\theta)}{2 \beta\left(4-\theta^{2}\right)(1+\theta)}, \\
p_{e}^{\mathrm{WP} *}=\frac{\left(2-\theta^{2}\right)\left((1-\theta)(2 \theta+3)+\theta \beta c_{T}\right)+\theta\left(1-\theta-\beta c_{T}\right)}{2 \beta\left(4-\theta^{2}\right)\left(1-\theta^{2}\right)} .
\end{gathered}
$$

The prices of the books under agency pricing model are given by

$$
\begin{gathered}
p_{T}^{2 *} \\
=\frac{\beta c_{T}\left(-2 \alpha+\alpha \theta^{2}+\theta^{2}\right)-6 \alpha+3 \alpha \theta+5 \alpha \theta^{2}-2 \alpha \theta^{3}-\alpha^{2} \theta+\alpha^{2} \theta^{2}}{\left(\alpha \theta^{2}(6+\alpha)-8 \alpha+\theta^{2}\right) \beta}, \\
p_{e}^{2 *}=\frac{-4 \alpha+\alpha \theta\left(1-\beta c_{T}\right)+\alpha\left(3 \theta^{2}+\theta\right)-\theta+\theta^{2}}{\left(\alpha \theta^{2}(6+\alpha)-8 \alpha+\theta^{2}\right) \beta} .
\end{gathered}
$$

And we can see that the prices of the books are lower under agency pricing model.

Proof of Proposition 6. The first-order derivatives of the total profit of the whole system with respect to the retail prices are as follows:

$$
\frac{\partial \text { Total }}{\partial p_{T}}=\frac{S\left(\mu \beta c_{T}+\mu-\mu \theta+\theta \beta p_{e}-2 \mu \beta p_{T}\right)}{1-\theta},
$$

$$
\begin{aligned}
& \frac{\partial \text { Total }}{\partial p_{e}} \\
& =\frac{S\left(-\mu \theta \beta c_{T}-2 \beta p_{e}+2 \mu \beta p_{e}+1-\theta+\theta \beta p_{T}-\mu+\mu \theta\right)}{1-\theta} .
\end{aligned}
$$

The second-order derivatives of the profit of retailer with respect to the retail prices are as follows:

$$
\frac{\partial^{2} \text { Total }}{\partial p_{T}^{2}} \frac{\partial^{2} \text { Total }}{\partial p_{e}^{2}}-\left(\frac{\partial^{2} \text { Total }}{\partial p_{T} \partial p_{e}}\right)^{2}=\frac{-S^{2} \beta^{2}\left(-4 \mu+4 \mu^{2}+\theta^{2}\right)}{(1-\theta)^{2}} .
$$

Proof of Proposition 8. The second-order derivatives of the profit of retailer with respect to the retail prices are as follows:

$$
\frac{d^{2} g_{T}}{d p_{T}^{2}}=\frac{-2 \mu S \beta}{1-\theta}<0
$$

And the second-order derivatives of the profit of the publisher with respect to wholesale prices are given by

$$
\begin{aligned}
& \frac{\partial^{2} g_{p}}{\partial w_{T}^{2}} \frac{\partial^{2} g_{p}}{\partial p_{e}^{2}}-\left(\frac{\partial^{2} g_{p}}{\partial w_{T} \partial p_{e}}\right)^{2} \\
& =\frac{-\beta^{2} S^{2}\left(\alpha \mu(1-\mu)\left(-8+\theta^{2}(6-\alpha)\right)+\theta^{2}\left(\alpha^{2}(1-\mu)+\mu^{2}\right)\right)}{4(1-\theta)^{2}} .
\end{aligned}
$$

Proof of Proposition 9. The second-order derivatives of the profit of retailer with respect to the retail prices are as follows:

$$
\frac{d^{2}\left(g_{T}+g_{e}\right)}{d p_{T}^{2}}=\frac{-2 \mu S \beta}{1-\theta}<0
$$

And the second-order derivatives of the profit of the publisher with respect to wholesale prices are given by

$$
\begin{aligned}
\frac{\partial^{2} g_{p}}{\partial w_{T}^{2}} \frac{\partial^{2} g_{p}}{\partial p_{e}^{2}}-\left(\frac{\partial^{2} g_{p}}{\partial w_{T} \partial p_{e}}\right)^{2} \\
\quad=\frac{\beta^{2} S^{2}\left(4 \mu(1-\mu)\left(2 \alpha\left(1-\theta^{2}\right)+\theta^{2}\right)-\theta^{2}\right)}{4(1-\theta)^{2}} .
\end{aligned}
$$

From the previous analyses we can get the optimal profit functions under different cases as follows:

$$
\begin{aligned}
g_{T}^{1 *}= & \mu S(1+\theta)^{2}(1-\theta) \\
& \times\left(2 \mu(1-\mu)\left(1-\beta c_{T}\right)\left(\theta^{2}-2\right)+(1-\mu) \theta\right)^{2} \\
& \times\left(\beta\left(4 \mu(1-\mu)\left(2-\theta^{2}\right)^{2}-\theta^{2}\right)^{2}\right)^{-1}, \\
g_{e}^{1 *}= & \mu^{2} S(1-\mu)(1+\theta)^{2}(1-\theta) \\
& \times\left(2\left(2-\theta^{2}\right)(1-\mu)-\theta\left(1-\beta c_{T}\right)\right)^{2} \\
& \times\left(\beta\left(4 \mu(1-\mu)\left(2-\theta^{2}\right)^{2}-\theta^{2}\right)^{2}\right)^{-1},
\end{aligned}
$$




$$
\begin{aligned}
& g_{p}^{1 *}=\mu S(1-\mu)(1+\theta) \\
& \times\left(\left(\theta^{2}-2\right)\left(\mu\left(1-\beta c_{T}\right)^{2}+1-\mu\right)+\theta\left(1-\beta c_{T}\right)\right) \\
& \times\left(\beta\left(\theta^{2}-4 \mu(1-\mu)\left(2-\theta^{2}\right)^{2}\right)\right)^{-1}, \\
& g_{T}^{2 *}=\alpha^{2} \mu(1-\mu)^{2} S(1-\theta)(1+\theta)^{2} \\
& \times\left(\mu\left(2\left(1-\beta c_{T}\right)-\theta\right)-\alpha \theta(1-\mu)\right)^{2} \\
& \times\left(\beta \left(\mu(1-\mu) \alpha\left(6 \theta^{2}-8-\alpha \theta^{2}\right)\right.\right. \\
& \left.\left.+\alpha^{2} \theta^{2}(1-\mu)+\mu^{2} \theta^{2}\right)^{2}\right)^{-1}, \\
& g_{e}^{2 *}=(1-\alpha)(1-\mu) \mu^{2}(1+\theta) S \\
& \times\left(\alpha(1-\mu)\left(4-3 \theta^{2}-\theta\left(1-\beta c_{T}\right)\right)\right. \\
& \left.+\mu \theta\left(1-\beta c_{T}-\theta\right)\right) \\
& \times\left(\alpha(1-\mu)\left(4-2 \theta^{2}-\theta\left(1-\beta c_{T}\right)\right)-\mu \theta\left(1-\beta c_{T}\right)\right) \\
& \times\left(\beta \left(\mu(1-\mu) \alpha\left(6 \theta^{2}-8-\alpha \theta^{2}\right)\right.\right. \\
& \left.\left.+\alpha^{2} \theta^{2}(1-\mu)+\mu^{2} \theta^{2}\right)^{2}\right)^{-1}, \\
& g_{p}^{2 *}=\alpha \mu(1-\mu) S(1+\theta) \\
& \times\left(\alpha \theta(1-\mu)\left(\theta+1-\beta c_{T}\right)\right. \\
& \left.-\mu\left(1-\theta+\beta c_{T}\left(\theta-2+\beta c_{T}\right)\right)-2 \alpha(1-\mu)\right) \\
& \times\left(\mu(1-\mu) \alpha \beta\left(6 \theta^{2}-8-\alpha \theta^{2}\right)\right. \\
& \left.+\alpha^{2} \theta^{2} \beta(1-\mu)+\mu^{2} \theta^{2} \beta\right)^{-1}, \\
& g_{T}^{4 *}=\mu S(1-\mu)^{2}(1+\theta)\left(\left(1-\beta c_{T}\right)\left(\theta^{2}-2 \mu\right)+\theta(2 \mu-1)\right) \\
& \times\left(\theta-2 \mu\left(1-\beta c_{T}\right)\right) \times\left(4 \beta\left(-4 \mu+4 \mu^{2}+\theta^{2}\right)^{2}\right)^{-1}, \\
& g_{e}^{4 *}=\mu^{2}(1-\mu) S(1+\theta)\left(\theta\left(1-\beta c_{T}\right)(1-2 \mu)-2(1-\mu)+\theta^{2}\right) \\
& \times\left(\theta\left(1-\beta c_{T}\right)-2(1-\mu)\right) \times\left(4 \beta\left(-4 \mu+4 \mu^{2}+\theta^{2}\right)^{2}\right)^{-1}, \\
& g_{p}^{4 *} \\
& =\frac{\mu(1-\mu) S(1+\theta)\left(-\mu\left(1-\beta c_{T}\right)^{2}+\theta\left(1-\beta c_{T}\right)-(1-\mu)\right)}{2 \beta\left(-4 \mu+4 \mu^{2}+\theta^{2}\right)}, \\
& g_{T}^{5 *}=\alpha \mu(1-\mu)^{2} S(1+\theta)\left(\theta-2 \mu\left(1-\beta c_{T}\right)\right) \\
& \times\left((1-\mu)\left(\theta^{2}(1-\alpha)\left(1-\beta c_{T}\right)-\theta^{3}(2 \alpha-1)^{2}+\alpha \theta(4 \alpha-3)\right)\right. \\
& \left.+\mu\left(\left(3 \alpha \theta^{2}-\theta^{2}-2 \alpha\right)\left(1-\beta c_{T}\right)+\theta\left(\theta^{2}-2 \alpha \theta^{2}+\alpha\right)\right)\right) \\
& \times\left(\beta\left(\theta^{2}-4 \mu(1-\mu)\left(\theta^{2}-2 \alpha \theta^{2}+2 \alpha\right)\right)^{2}\right)^{-1} \text {, }
\end{aligned}
$$

$$
\begin{aligned}
g_{e}^{5 *}= & (1-\alpha) \mu(1-\mu)(1+\theta) \\
\times & S\left(\theta(1-2 \mu)\left(\theta-1+\beta c_{T}\right)+4 \alpha(1-\mu)\left(1-\theta^{2}\right)\right) \\
\times & \left(\mu(1-\mu)\left(\theta(1-2 \alpha)\left(2 \theta-\beta c_{T}\right)-2 \alpha \theta+2 \theta+4 \alpha\right)\right. \\
& \left.\quad+(1-\mu)\left(\alpha \theta^{2}-\theta^{2}+\theta\right)+\mu^{2} \theta \beta c_{T}-\theta\right) \\
& \times\left(\beta\left(\theta^{2}-4 \mu(1-\mu)\left(\theta^{2}-2 \alpha \theta^{2}+2 \alpha\right)\right)^{2}\right)^{-1} \\
g_{p}^{5 *}= & \alpha \mu(1-\mu)(1+\theta) \\
& \times S\left((1-\mu)\left(2 \alpha\left(1-\theta^{2}\right)+\theta^{2}\right)\right. \\
& \left.\quad+\beta c_{T}\left(\mu\left(\beta c_{T}-2\right)+\theta\right)+\mu-\theta\right) \\
& \times\left(\beta\left(4 \mu(1-\mu)\left(\theta^{2}-2 \alpha \theta^{2}+2 \alpha\right)-\theta^{2}\right)\right)^{-1} .
\end{aligned}
$$

\section{References}

[1] R. K. Chellappa and S. Shivendu, "Pay now or pay later? Managing digital product supply chains," in Proceeding of the 5th International Conference on Electric Commerce (ICEC '03), pp. 230-234, October 2003.

[2] Y. Feng, Supply Chain Models and Channel Strategies for Distributing Tangible and Intangible Products with the InternetEnabled Market [Doctor of Philosophy], University of Maryland, Baltimore, Md, USA, 2008.

[3] B.-K. Jeong, M. Khouja, and K. Zhao, “The impacts of piracy and supply chain contracts on digital music channel performance," Decision Support Systems, vol. 52, no. 3, pp. 590-603, 2012.

[4] M. Khouja and Y. Wang, "The impact of digital channel distribution on the experience goods industry," European Journal of Operational Research, vol. 207, no. 1, pp. 481-491, 2010.

[5] M. Khouja and S. Park, "Optimal pricing of digital experience goods under piracy," Journal of Management Information Systems, vol. 24, no. 3, pp. 109-141, 2007.

[6] M. Khouja and M. A. Smith, "Optimal pricing for information goods with piracy and saturation effect," European Journal of Operational Research, vol. 176, no. 1, pp. 482-497, 2007.

[7] B. Danaher, S. Dhanasobhon, M. D. Smith, and R. Telang, "Converting pirates without cannibalizing purchasers: the impact of digital distribution on physical sales and internet piracy," Marketing Science, vol. 29, no. 6, pp. 1138-1151, 2010.

[8] B. Deleersnyder, I. Geyskens, K. Gielens, and M. G. Dekimpe, "How cannibalistic is the Internet channel? A study of the newspaper industry in the United Kingdom and The Netherlands," International Journal of Research in Marketing, vol. 19, no. 4, pp. 337-348, 2002.

[9] P. Keskinocak and S. Tayur, "Quantitative analysis for internetenabled supply chains," Interfaces, vol. 31, no. 2, pp. 70-89, 2001.

[10] K. D. Cattani and W. G. Gilland, "Coordinating traditional and internet supply chains," in Supply Chain Analysis in the EBusiness Era, D. Simchi-Levi, D. Wu, and M. Shen, Eds., Kluwer Academic Publishers, 2003.

[11] N. A. H. Agatz, M. Fleischmann, and J. A. E. E. van Nunen, "Efulfillment and multi-channel distribution: a review," European 
Journal of Operational Research, vol. 187, no. 2, pp. 339-356, 2008.

[12] R. Lal and M. Sarvary, "When and how is the internet likely to decrease price competition?" Marketing Science, vol. 18, no. 4, pp. 485-503, 1999.

[13] E. Biyalogorsky and P. Naik, "Clicks and mortar: the effect of online activities on off-line sales," Marketing Letters, vol. 14, no. 1, pp. 21-32, 2003.

[14] G. Cai, "Channel selection and coordination in dual-channel supply chains," Journal of Retailing, vol. 86, no. 1, pp. 22-36, 2010.

[15] P. I. Jeffers and B. R. Nault, "Why competition from a multichannel E-tailer does not always benefit consumers*," Decision Sciences, vol. 42, no. 1, pp. 69-91, 2011.

[16] C. Forman, A. Ghose, and A. Goldfarb, "Competition between local and electronic markets: how the benefit of buying online depends on where you live," Management Science, vol. 55, no. 1, pp. 47-57, 2009.

[17] W. Huang and J. M. Swaminathan, "Introduction of a second channel: implications for pricing and profits," European Journal of Operational Research, vol. 194, no. 1, pp. 258-279, 2009.

[18] Q. Lu and N. Liu, "Pricing games of mixed conventional and e-commerce distribution channels," Computers and Industrial Engineering, vol. 64, no. 1, pp. 122-132, 2013.

[19] S. Jain and P. K. Kannan, "Pricing of information products on online servers: issues, models, and analysis," Management Science, vol. 48, no. 9, pp. 1123-1142, 2002.

[20] Y.-J. Chen and S. Seshadri, "Product development and pricing strategy for information goods under heterogeneous outside opportunities," Information Systems Research, vol. 18, no. 2, pp. 150-172, 2007.

[21] A. Szolnoki, M. Perc, and G. Szabó, "Defense mechanisms of empathetic players in the spatial ultimatum game," Physical Review Letters, vol. 109, no. 7, Article ID 079701, 2012.

[22] A. Szolnoki, M. Perc, and G. Szabó, "Accuracy in strategy imitations promotes the evolution of fairness in the spatial ultimatum game," Europhysics Letters, vol. 100, Article ID 28005 , 2012.

[23] W. A. Shelburne, "E-book usage in an academic library: user attitudes and behaviors," Library Collections, Acquisition and Technical Services, vol. 33, no. 2-3, pp. 59-72, 2009.

[24] A. M. Petersen, J. N. Tenenbaum, S. Havlin, H. E. Stanley, and M. Perc, "Languages cool as they expand: allometric scaling and the decreasing need for new words," Scientific Reports, vol. 2, article 943, 2012.

[25] J. Gao, J. Hu, X. Mao, and M. Perc, "Culturomics meets random fractal theory: insights into long-range correlations of social and natural phenomena over the past two centuries," Journal of the Royal Society Interface, vol. 9, pp. 1956-1964, 2012.

[26] M. Perc, "Evolution of the most common English words and phrases over the centuries," Journal of the Royal Society Interface, vol. 9, pp. 3323-3328, 2012.

[27] M. Pölönen, T. Järvenpää, and J. Häkkinen, "Reading e-books on a near-to-eye display: comparison between a small-sized multimedia display and a hard copy," Displays, vol. 33, pp. 157167, 2012.

[28] W. D. Woody, D. B. Daniel, and C. A. Baker, "E-books or textbooks: students prefer textbooks," Computers and Education, vol. 55, no. 3, pp. 945-948, 2010.

[29] L.-Y. Huang and Y.-J. Hsieh, "Consumer electronics acceptance based on innovation attributes and switching costs: the case of e-book readers," Electronic Commerce Research and Applications, vol. 11, pp. 218-228, 2012.
[30] Y. Jiang and E. Katsamakas, "Impact of e-book technology: ownership and market asymmetries in digital transformation," Electronic Commerce Research and Applications, vol. 9, no. 5, pp. 386-399, 2010.

[31] G. Hua, T. C. E. Cheng, and S. Wang, "Electronic books: to "e" or not to "e"? A strategic analysis of distribution channel choices of publishers," International Journal of Production Economics, vol. 129, no. 2, pp. 338-346, 2011.

[32] T. W. McGuire and R. Staelin, "An industry equilibrium analysis of downstream vertical integration," Marketing Science, vol. 2, no. 2, pp. 161-191, 1983.

[33] R. Slater, "E-books or print books, "big deals" or local selections. What gets more use?" Library Collections, Acquisition and Technical Services, vol. 33, no. 1, pp. 31-41, 2009.

[34] J. Hilton and D. Wiley, "Free E-Books and print sales," Journal of Electronic Publishing, vol. 14, no. 1, 2011.

[35] Y.-Y. Kang, M.-J. J. Wang, and R. Lin, "Usability evaluation of E-books," Displays, vol. 30, no. 2, pp. 49-52, 2009.

[36] A. Yu, Y. Hu, and M. Fan, "Pricing strategies for tied digital contents and devices," Decision Support Systems, vol. 51, no. 3, pp. 405-412, 2011. 


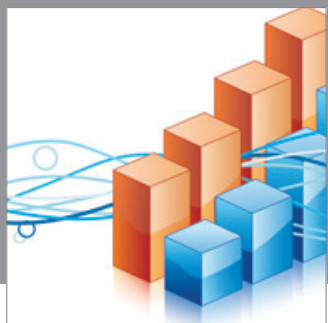

Advances in

Operations Research

mansans

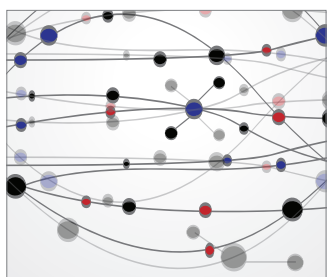

The Scientific World Journal
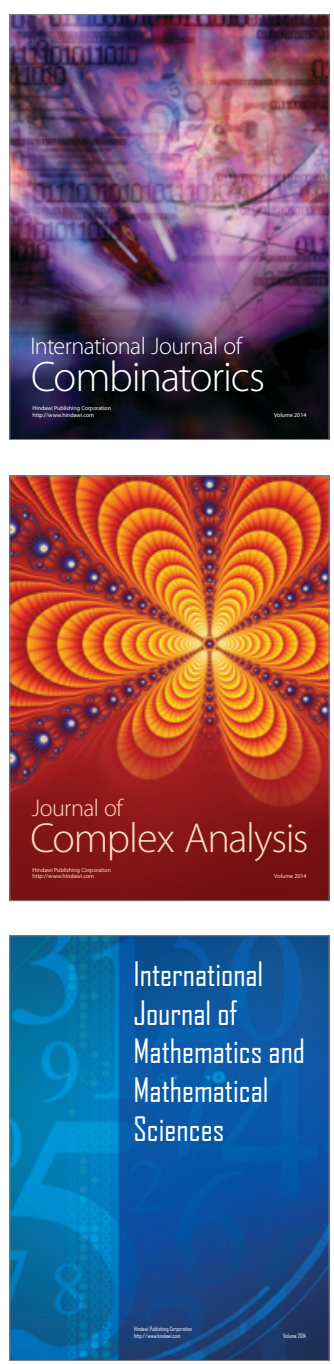
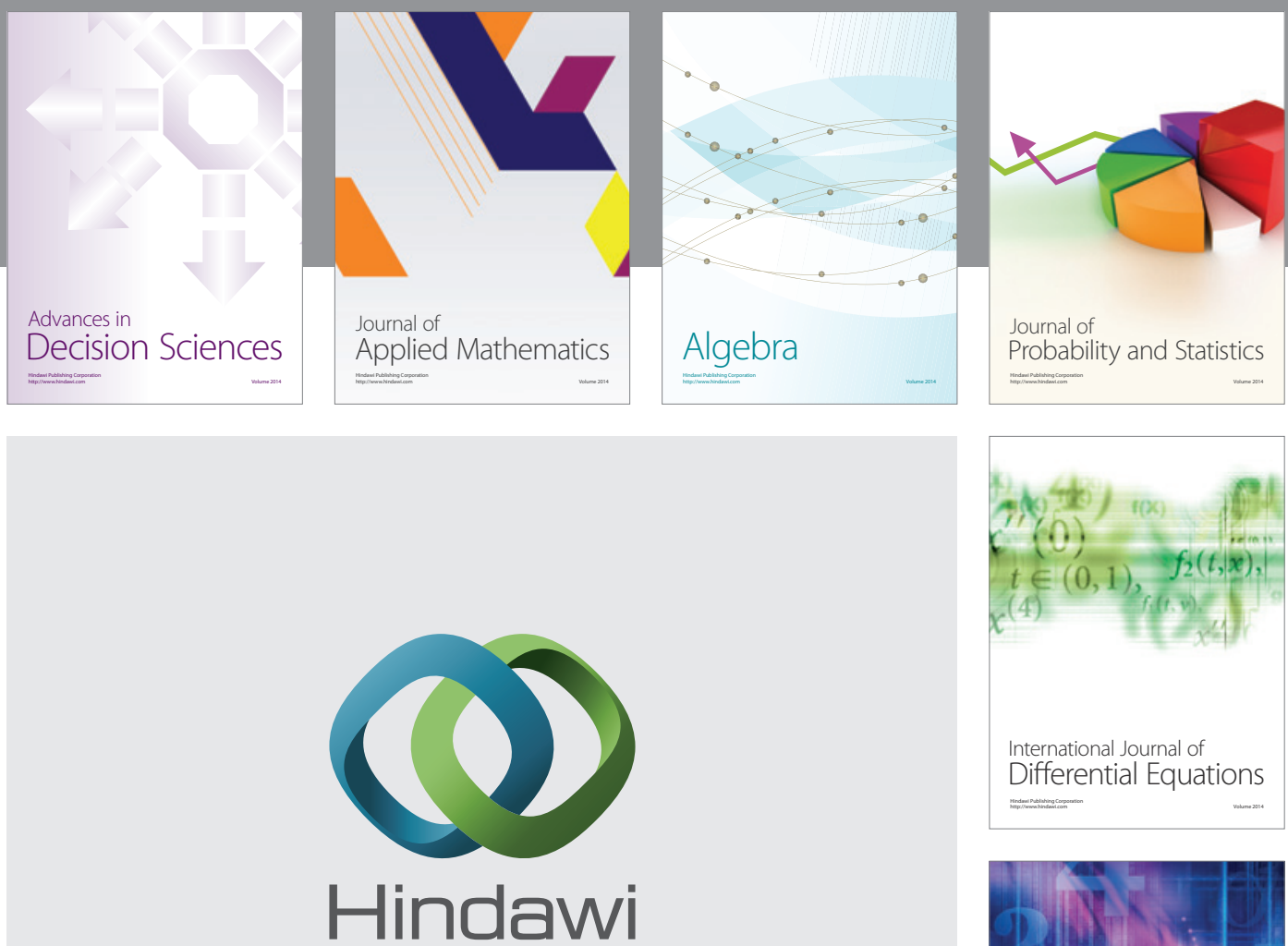

Submit your manuscripts at http://www.hindawi.com
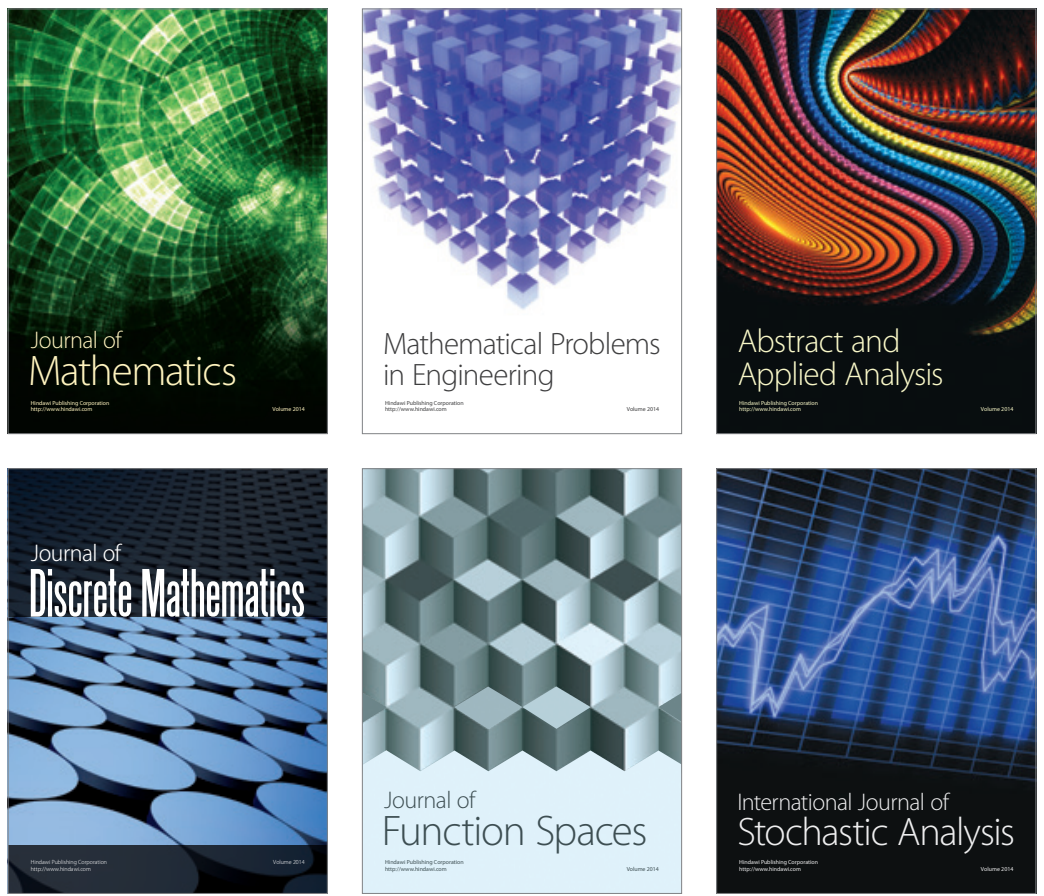

Journal of

Function Spaces

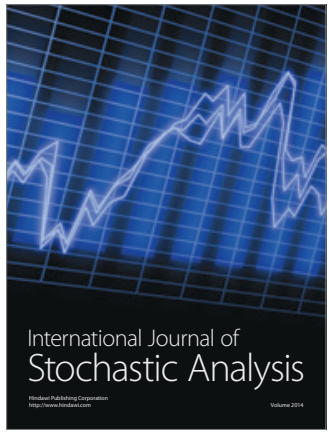

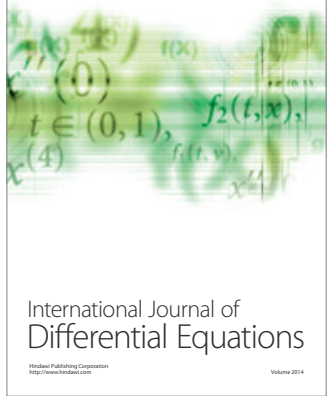
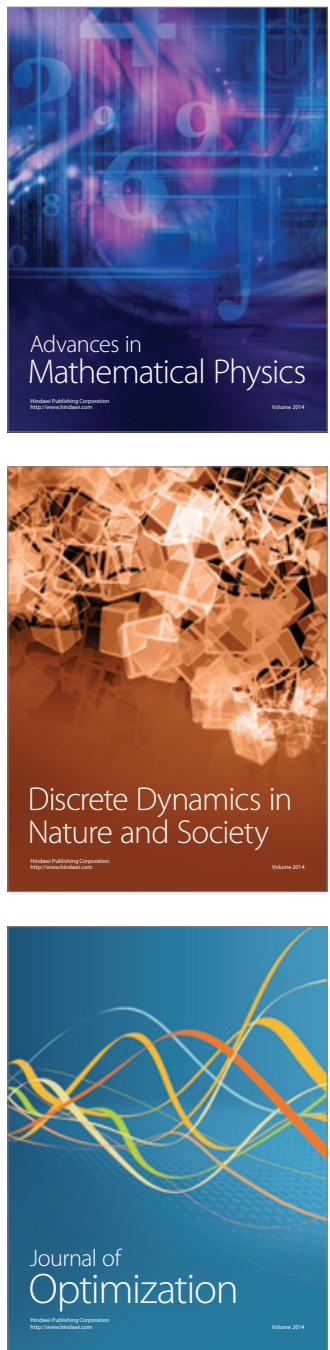